\title{
Belbin's team roles and their performance in road design courses: a study with undergraduate and postgraduates students
}

\section{Los roles del equipo de Belbin y su desempeño en los cursos de diseño de carreteras: un estudio con alumnos de pregrado y posgrado}

GARCÍA-RAMÍREZ, Yasmany D. ${ }^{1}$

\begin{abstract}
This article analyzes the relationship between the Belbin's team roles and their performance in road design courses. Data were collected from four Civil Engineering groups (undergraduate and postgraduates students) divided into 25 teams. As a result, a consistent relationship was not found between the team balance and its performance in all teams. However, the three most influential roles in performance were identified, but this was only relevant to postgraduate students.

Key words: belbin's team roles, performance, road design courses, undergraduate and postgraduates students

Resumen

Este artículo analiza la relación entre los roles del equipo de Belbin y su rendimiento en cursos de diseño de carreteras. Se recolectaron datos de cuatro grupos de Ingeniería Civil (pregrado y posgrado) divididos en 25 equipos. Como resultados no se encontró una relación consistente entre el balance del equipo y su rendimiento en todos los equipos. Sin embargo, se identificaron los tres roles más influyentes en el rendimiento, pero esto sólo fue relevante para los estudiantes de posgrado.

Palabras clave: roles del equipo de belbin, rendimiento, cursos de diseño de carreteras, estudiantes de pregrado y posgrado
\end{abstract}

\section{Introduction}

Organizations require their employees to have, in addition to knowledge and expertise, teamwork skills (Stevens \& Campion, 1999). Given this need, universities within their curriculum create various spaces to promote this competence. One of the ways to develop it is through collaborative learning (Curşeu et al., 2012), especially experiencing authentic problems across the course units (McCune \& Entwistle, 2011). Collaborative learning, as a project-based approach, allows students to work together to achieve a common goal, benefiting the team as well as its members. In a teaching context, in engineering majors, teamwork is a highly powerful technique (Gutiérrez et al., 2019). Therefore, the team characteristics that allow it to be most effective must be identified (Curşeu \& Pluut, 2013).

One of the tools that are widely used to estimate these characteristics is Belbin's diagnostic instrument for team role self-perception. It allows knowing the roles that people prefer when they work in teams. It was proposed by

\footnotetext{
${ }^{1}$ Researcher. Civil Engineering Department. Universidad Técnica Particular de Loja (UTPL). Ecuador. Email: ydgarcia1@utpl.edu.ec
} 
Belbin, after a 6-year experimental study (Belbin, 1981). It has been used in the workplace and undergraduate and postgraduate education (Belbin, 2019). The instrument has seven sections and each section has nine items, one for each of the nine roles: shaper (SH), implementer (IM), complementer finisher (CF), plant ( $\mathrm{PL}$ ), monitorevaluator (ME), specialist (SP), co-ordinator (CO), resource investigator (RI), and teamworker (TW) (Belbin, 2009). They can group them in action (SH, IM, CF), mental (PL, ME, SP), and social roles (CO, RI, TW). The Shaper is challenging, dynamic, and performs well under pressure. The Implementer turns ideas into actions and organizes the work that needs to be done. Complementer-finisher searches out errors, and polishes and perfects details. The Plant generates ideas and solves difficult problems. The Monitor-evaluator analyzes all options and judges accurately. A Specialist is single-minded, self-starting, and dedicated. Co-ordinator clarifies goals and delegates effectively. Resource investigator is outgoing, enthusiastic, and communicative. Teamworker is co-operative, perceptive, and diplomatic. Each of these roles makes its contribution to the team and therefore they complement each other, as long as the team is balanced.

Belbin's role theory proposes that a balanced teams (possessing all nine roles) has better performance than an unbalanced, in which there are duplicate roles (Belbin, 1981). For example, a team where all members are coordinators may have worse performance than one where other roles are present. In a team, implement and teamworker role are the repeated roles that are allowed, which is beneficial for the team (Belbin, 1981). The Belbin theory also recognizes that behaviors are contextual and will change over time in response to new circumstances. The latest version of Belbin, in addition to self-perception, also integrates observers' opinions to complete the role analysis (Belbin, 2019). The Belbin theory, which measures behavior rather than personality (Smith et al., 2012), has been widely used in several areas. However, empirical evidence does not yet have conclusive results about the relationship between team role balance and team performance (Blenkinsop \& Maddison, 2007; Prichard \& Stanton, 1999; van de Water et al., 2008).

Until now, the literature reports results for and against the theory. For example, in a management course, no relationship was found between the diversity of 24 teams and their performance (Smith et al., 2012). A study from 43 teams of MBA students did not find a significant relationship between team role balance and team performance (Partington \& Harris, 1999). Another study in the Organizational Behavior course with 84 teams found that the group role balance positively predicts the group performance in preliminary phases of the group project but not in later phases (Meslec \& Curşeu, 2015). In the management area, six mixed teams of four individuals (one co-ordinator, one plant, one completer finisher, and one teamworker) performed better than teams consisting of shapers alone (Prichard \& Stanton, 1999). In the Development of Software Requirements course, there was a statistically significant difference in the quality of the products generated by teams with compatible roles, compared to the quality of the products generated by randomly integrated teams (Aguilar et al., 2020). In nine engineering subjects with 49 teams developed some models to predict the team performance based on the Belbin test results (Gutiérrez et al., 2019). Likewise, a study in a food industry suggested that the teams are complemented in their disabled characteristics, so being able to balance the profiles; and thus get the best results from each team (Moraes \& Loos, 2017). A study in three different disciplines: business, engineering, and occupational therapy found that the implementer role had features and positive qualities which are essential to successful project execution and in minor impact the shaper and co-ordinator (Sommerville \& Dalziel, 1998). In a sample of 32 project management teams, a statistical relation between team role balance and team motivation was found (Lupuleac et al., 2012). In conclusion, research has been found positive and negative results, so it is still possible to delve into Belbin's role theory or in their application.

This in-deep analysis will reveal ways to promote teamwork, especially in the area of engineering In Civil Engineering there is just one previous study (Gutiérrez et al., 2019), while in the area of Road Engineering, part of Civil Engineering, also one preliminary research from the author (García-Ramírez, 2020). Even though it is an area where teamwork is mandatory given the complexity of the design, construction, and operation of the roads. 
Therefore, the objective of this study is to analyze the relationship between Belbin's team role results and their performance in road design courses. To do this, two research questions were raised: is there any relationship between the team's balanced and its performance? Do some or some roles in the team influence most their performance? Four groups of students participated in the study (undergraduate and postgraduate) who took courses related to road design.

To explain the results of this research, the rest of the article is organized as follows. In the methodology section details the selection of the sample, the main elements of the course, the measurement instruments, the data collection and processing procedure, and the organization of students in the teams. Then, in the results section, the students' perception of the tool is explained, the team's performance is analyzed to answer the two research questions, and finally, the comments about the teamwork of the students are presented. Finally, the main conclusions of the work are highlighted.

\section{Methodology}

The two variables that need to be analyzed are the characteristics of the teams and their performance. Roles were estimated based on the Belbin's team role self-perception survey, while their performance was assumed as the team's final grades. These scores were calculated by the instructor. The elements necessary to calculate these two variables are detailed below.

\subsection{Sample selection}

Four groups of students from the Civil Engineering major participated in the study: two undergraduate and two postgraduate, as shown in Table 1. The first three were regular courses of 4 months duration (once a week), while, the last one was performed in a month (three times a week). The main topic of all courses was the geometric design of rural roads. Learning method in all subjects was based on project-based learning with a highway project. The undergraduate students were around 20 years old, while the master's students were of various ages, but older than 25 years. The master's students were civil engineers in free professional practice or employees of public or private companies. The first three courses were delivered at the Universidad Técnica Particular de Loja (Loja province), while the last was at the Universidad de Cuenca (Azuay province), in Ecuador.

Table 1

Detail of the courses participating in the study

\begin{tabular}{|c|c|c|c|c|c|c|}
\hline Group & Course & $\begin{array}{c}\text { Number of } \\
\text { students }\end{array}$ & University & Career & Study mode & $\begin{array}{c}\text { Academic } \\
\text { period }\end{array}$ \\
\hline A & $\begin{array}{c}\text { Road } \\
\text { construction I }\end{array}$ & 41 & $\begin{array}{c}\text { Universidad Técnica } \\
\text { Particular de Loja }\end{array}$ & $\begin{array}{c}\text { Civil } \\
\text { Engineering }\end{array}$ & Undergraduate & $\begin{array}{c}\text { April-August } \\
2020\end{array}$ \\
\hline B & $\begin{array}{c}\text { Road } \\
\text { construction I }\end{array}$ & 25 & $\begin{array}{c}\text { Universidad Técnica } \\
\text { Particular de Loja }\end{array}$ & $\begin{array}{c}\text { Civil } \\
\text { Engineering }\end{array}$ & Undergraduate & $\begin{array}{c}\text { April-August } \\
2020\end{array}$ \\
\hline C & Road project & 25 & $\begin{array}{c}\text { Universidad Técnica } \\
\text { Particular de Loja }\end{array}$ & $\begin{array}{c}\text { Mountain } \\
\text { roads }\end{array}$ & Postgraduate & April-August \\
2020
\end{tabular}

Source: Prepared by the author based on course details

\subsection{Course details}

All courses had the same instructor. Due to restrictions due to COVID-19, sessions were delivered exclusively online. These sessions were held on the Zoom platform (Zoom Video Comunications Inc., 2020). In undergraduate courses, sessions lasted 5 hours, while in postgraduate courses, 3 hours. Students were organized 
into teams (about five students per team) using the same platform that is called small groups. With this tool, members of the team interact with each other, which is hard in a regular session. Also, they can call the instructor to ask questions, so they receive what the team needs. And the instructor can enter the small groups to review their progress. In the academic activities, there were individual such as problem-solving, exams, etc., and in teams such as presentations, project development, project writing, and delivery, among others.

\subsection{Data collection instruments}

The data collection instruments were three: the Belbin role survey, a general questionnaire of students, and the final grades of the teams. With the first, the preferred roles of the students were estimated. It also served to organize the students into teams. The second instrument helped to know the students' perception of teamwork. The third was used as a measure of team performance. All statistical analyzes were performed using the Minitab 14.2 program (State College, 2005).

\subsection{Data collection and processing}

The data collection was carried out in two moments: at the beginning and the end of the courses. Firstly, students answered the Belbin survey. Based on these results, learners were organized in teams (the details of which are described later). The survey has seven sections, where students had to distribute ten points across the nine items that every section has. This distribution was base on the behavior that best described them when they work in a group. A final Belbin score was computed for each group member for each of the nine roles. Theoretically, each role score can take values between 0 and 70 . Students answered about the Belbin survey results and their relationship to their reality ( $1=$ strongly disagree, $10=$ strongly agree). The average of these values was calculated with the $95 \%$ confidence index.

The students were also asked, through open questions, about their perception of teamwork. This was conducted at the end of the course, where they answered about the usefulness of the Belbin survey, satisfaction with the team, and general comments about the experience. The survey was anonymous and optional. Their responses were categorized, and their percentages were calculated. On the other hand, team final grades were a measure of team performance. These grades only included activities carried out as a team. For each submitted assignment, all members received the same grade. All these academic activities were evaluated employing rubrics, which were shared with the students from the first day. Team scores could reach a score up to 10 points.

\subsection{Organizing students to teams}

The organization of students in the teams was made by considering the Belbin survey results of each student. It adopted the procedure described in previous research (García-Ramírez, 2020). This procedure includes cluster analyzes. Thus, students with a high level of similarity were placed on different teams, so they were more equitable teams. Despite this procedure, a single student could have multiple groupings or combinations. Then, it employed the average values of the nine roles for each course. Also, it summed the scores of each of the roles in each team (team roles). This value could not exceed 10 points up or down from the average values of the group course. Students were then assigned or removed until this condition was met. However, it could not be fulfilled in all groups due to the variations inherent in the roles. So in each group, there was a team that slightly exceeded this threshold. The results of the teams for the four groups can be seen in figure 1. Most of the teams in all the courses had five members, except for two groups from course $A$ and $D$. 
Figure 1

Distribution of the students in the teams in the four groups under study

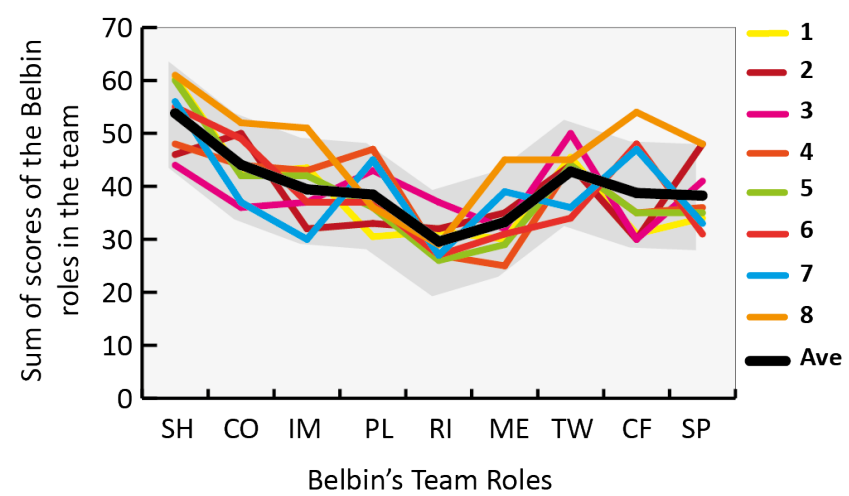

A) Sum of scores of the Belbin roles for the group A

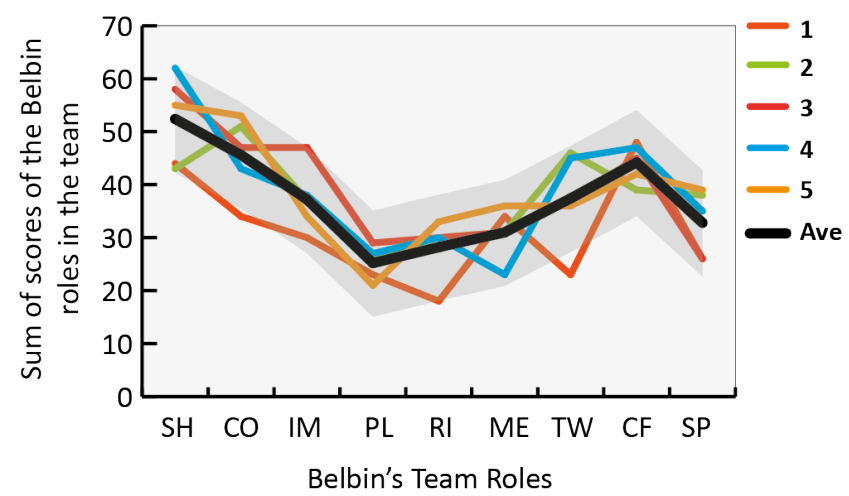

C) Sum of scores of the Belbin roles for the group C

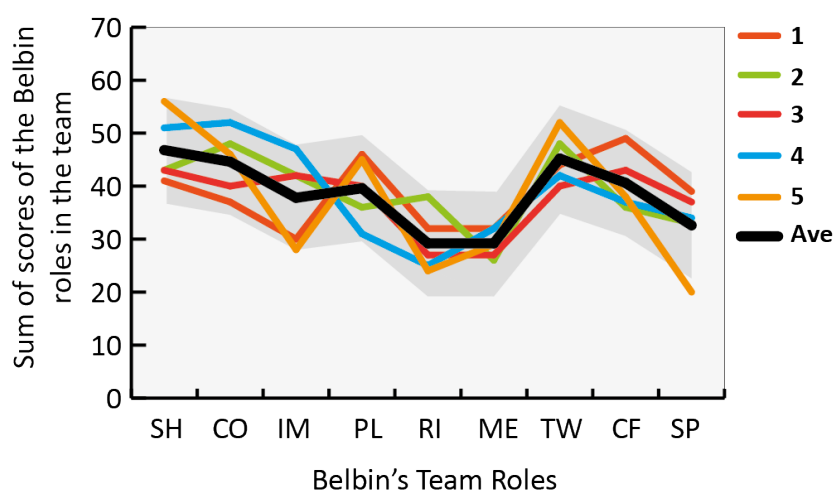

B) Sum of scores of the Belbin roles for the group B

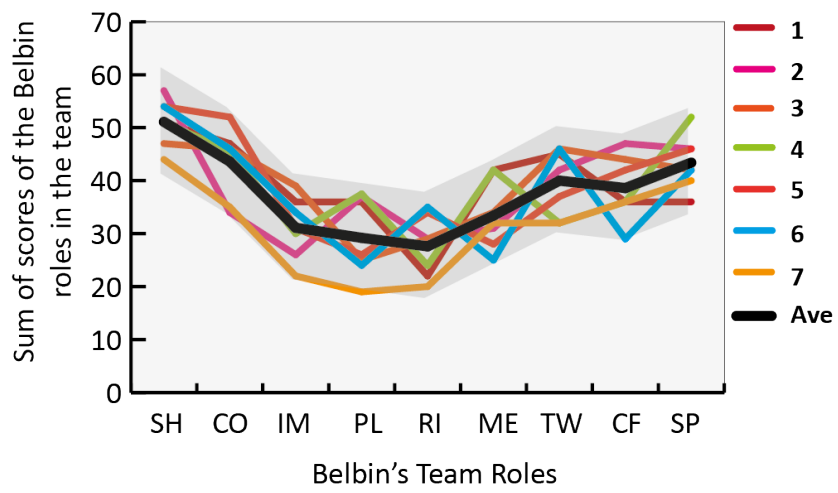

D) Sum of scores of the Belbin roles for the group D

SH: Shaper, CO: Co-ordinador, IM: implementer, PL: plant, RI: Resource Investigator, ME: monitor-evaluador, TW: Teamworker, CF: Complementer finisher, SP: Specialist

Source: Prepared by the author based on Belbin's team role self-perception results

Figure 1 shows that the four lines of average values have some similarity between them. Low values are presented in the central roles, and the high ones are in the outermost. The lowest values of the four trend lines are around 30 points and go up to approximately 50 points. On average, in groups A, B, and C, the Resource investigator was the lowest role, while in group $C$ it was the Plant, although the Resource investigator was the next lowest role. On the other hand, in all groups, the Shaper role was the one with the highest average value. These trends could be a particular characteristic of the Civil Engineering career (students and professionals).

\subsection{Group Balance Metrics (GBMs)}

In order to answer the first research question about the balanced teams, it calculated the Group Balance Metrics or $\mathrm{GBMs}\left(\mathrm{GBM}_{1}, \mathrm{GMB}_{2}, \mathrm{GMB}_{3}\right.$, and $\left.\mathrm{GMB}_{4}\right)$. This metrics were calculated according to the methodology in a previous study (Smith et al., 2012). The $\mathrm{GBM}_{1}$ (from 0 to 100\%) represents whether a team has strong role examples among its members. A $100 \%$ means that the team has all nine roles, while 0 means that it has none. $\mathrm{GBM}_{1}$ is calculated as:

$$
\operatorname{GBM}_{1}(\%)=100 \frac{r}{B}
$$


Where $B$ is the number of Belbin roles (in this case 9), and $r$ is the number of roles that are represented in the team. A strong example refers to when the scores exceed a certain percentage or value in each team member. Some studies have used $80 \%$ (Smith et al., 2012) or the value of 17 points (Partington \& Harris, 1999). If a constant value is chosen for all roles in Civil Engineering, the lowest roles may not achieve that value (see figure 1). Just a few of them will do, for example, SH or $\mathrm{CO}$. To be more precise, different thresholds were calculated for each role: 16 (SH), 15 (CO), 15 (IM), 14 (PL), 12 (RI), 12 (ME), 15 (TW), 14 (CF) and 13 (SP). When a person's scores exceed those values, it can be said to have a dominant role and would correspond to a strong example on the team. The thresholds were got from the 95th percentile in each role of the entire sample in this study.

The $\mathrm{GMB}_{2}$ determines if a dominant role is duplicated in the team. That is, when there are two or more people who exceed the thresholds used in the $\mathrm{GBM}_{1}$. According to Belbin, there should be no duplicate roles in a team, unless they are Teamwork or Shaper roles, which, in those cases, is beneficial for the team (Belbin, 1981). It is also measured in percentage (0-100\%), where 100 means there are no duplicate roles. $\mathrm{GBM}_{2}$ is calculated as:

$$
\operatorname{GBM}_{2}(\%)=100 \frac{(n-1)-d}{(n-1)}
$$

Where $d$ is the number of duplicate strong examples in any role, while $\mathrm{n}$ is the number of team members. Since a person can have more than one strong role, this index can have negative values. On the other hand, the $\mathrm{GBM}_{3}$ : average Belbin score (out of 100) of the weakest two roles measured by the highest individual scoring in that role, and the $\mathrm{GBM}_{4}$ : average Belbin score (out of 100) of the weakest two roles measured by the group average score.

\section{Results}

Results have been divided into three sub-sections: adjustment of Belbin results, analysis of team performance, and final comments from students.

\subsection{Student perception about Belbin results}

After the Belbin survey, at the beginning of the courses, each student was asked how accurate they think the results of the survey are ( $1=$ strongly disagree, $10=$ strongly agree). All groups responded with high values: group A: 7.94 [8.30, 7.58], group B: 7.40 [6.57, 8.23], group C: 8.16 [7.71, 8.61] and group D: 8.12 [7.77, 8.47]. Therefore, the Belbin questionnaire resembles the role perceived by the student when they work in a team. It is interesting that the values of the graduate groups are slightly higher than the undergraduate groups and that they are also very similar to each other. Belbin's role self-perception also makes students aware of themselves, of the roles that they can take when working in teams, of their boundaries.

\subsection{Team performance}

As previously mentioned, the team's final grade was considered as the performance of the team. Two analyzes of the team's performance and its relationship with their preferred Belbin roles were carried out: GBMs (first study question) and the sum of Belbin roles in each team (second study question). The final grades, the values of the nine roles in each group, and the team balance measures can be seen in Table 2. 
Table 2

Sum of Belbin Role Scores, Group Balance Metrics and final grades of all teams

Sum of Belbin Role Scores

GBM

Final

\begin{tabular}{|c|c|c|c|c|c|c|c|c|c|c|c|c|c|c|c|}
\hline \multirow{2}{*}{ Group } & \multirow{2}{*}{$\mathbf{N}^{\circ}$} & & & \multirow{2}{*}{$\begin{array}{c}\text { grades } \\
\text { (points) }\end{array}$} \\
\hline & & SH & $\mathrm{CO}$ & IM & PL & $\mathbf{R I}$ & ME & TW & CF & SP & 1 & 2 & 3 & 4 & \\
\hline \multirow{8}{*}{ A } & 1 & 61 & 43 & 44 & 31 & 32 & 30 & 46 & 31 & 34 & 22 & 75 & 20 & 26 & $7.39 \downarrow$ \\
\hline & 2 & 46 & 50 & 32 & 33 & 32 & 35 & 44 & 30 & 48 & 22 & 50 & 15 & 26 & 9.42 \\
\hline & 3 & 44 & 36 & 37 & 43 & 37 & 32 & 50 & 30 & 41 & 22 & 75 & 0.0 & 0.0 & 8.47 \\
\hline & 4 & 48 & 44 & 43 & 47 & 27 & 25 & 44 & 35 & 36 & 11 & 50 & 9 & 13 & 9.06 \\
\hline & 5 & 60 & 42 & 42 & 36 & 26 & 29 & 44 & 35 & 35 & 44 & 75 & 6 & 13 & 8.23 \\
\hline & 6 & 55 & 49 & 37 & 37 & 27 & 31 & 34 & 48 & 31 & 33 & 75 & 0 & 0 & $9.61 \uparrow$ \\
\hline & 7 & 56 & 37 & 30 & 45 & 27 & 39 & 36 & 47 & 33 & 44 & 75 & 0 & 0 & 8.70 \\
\hline & 8 & 61 & 52 & 51 & 36 & 29 & 45 & 45 & 54 & 48 & 78 & 80 & 0 & 0 & 8.56 \\
\hline \multirow{5}{*}{ B } & 1 & 41 & 37 & 30 & 46 & 32 & 32 & 44 & 49 & 39 & 44 & 75 & 8 & 13 & $8.82 \uparrow$ \\
\hline & 2 & 43 & 48 & 42 & 36 & 38 & 26 & 48 & 36 & 33 & 33 & 75 & 21 & 39 & 7.86 \\
\hline & 3 & 43 & 40 & 42 & 40 & 27 & 27 & 40 & 43 & 37 & 0.0 & 75 & 17 & 27 & $7.82 \downarrow$ \\
\hline & 4 & 51 & 52 & 47 & 31 & 25 & 32 & 42 & 37 & 34 & 11 & 75 & 15 & 26 & 8.52 \\
\hline & 5 & 67 & 51 & 37 & 51 & 27 & 39 & 61 & 49 & 26 & 11 & 75 & 0 & 0 & 7.92 \\
\hline \multirow{5}{*}{ C } & 1 & 44 & 34 & 30 & 23 & 18 & 34 & 23 & 48 & 26 & 33 & 75 & 10 & 26 & 8.17 \\
\hline & 2 & 43 & 51 & 37 & 26 & 30 & 31 & 46 & 39 & 38 & 22 & 75 & 7 & 26 & 8.23 \\
\hline & 3 & 58 & 47 & 47 & 29 & 30 & 31 & 37 & 45 & 26 & 44 & 50 & 18 & 26 & $8.38 \uparrow$ \\
\hline & 4 & 62 & 43 & 38 & 27 & 30 & 23 & 45 & 47 & 35 & 56 & 75 & 0 & 0 & 8.21 \\
\hline & 5 & 55 & 53 & 34 & 21 & 33 & 36 & 36 & 42 & 39 & 11 & 75 & 0 & 0 & $7.70 \downarrow$ \\
\hline \multirow{7}{*}{ D } & 1 & 51 & 47 & 36 & 36 & 22 & 42 & 45 & 36 & 36 & 22 & 75 & 5 & 13 & 8.60 \\
\hline & 2 & 57 & 34 & 26 & 37 & 29 & 31 & 42 & 47 & 46 & 22 & 75 & 12 & 26 & $9.53 \uparrow$ \\
\hline & 3 & 47 & 46 & 39 & 25 & 29 & 34 & 46 & 44 & 42 & 33 & 75 & 15 & 26 & 9.30 \\
\hline & 4 & 51 & 46 & 30 & 38 & 24 & 42 & 32 & 36 & 52 & 33 & 50 & 15 & 37 & 9.24 \\
\hline & 5 & 54 & 52 & 31 & 26 & 34 & 28 & 37 & 42 & 46 & 11 & 75 & 0 & 0 & 9.47 \\
\hline & 6 & 54 & 46 & 34 & 24 & 35 & 25 & 46 & 29 & 42 & 44 & 50 & 6 & 13 & $8.39 \downarrow$ \\
\hline & 7 & 44 & 35 & 22 & 19 & 20 & 32 & 32 & 36 & 40 & 33 & 67 & 25 & 39 & 9.43 \\
\hline
\end{tabular}

SH: Shaper, CO: Co-ordinador, IM: implementer, PL: plant, RI: Resource Investigator, ME: monitor-evaluador, TW:

Teamworker, CF: Complementer finisher, SP: Specialist. $\uparrow$ Highest grade in the group. $\downarrow$ Lowest grade in the group.

Source: Prepared by the author based on this study results

Group performance was compared with GBMs to assess whether more balanced teams led to a better overall group performance. The most balanced teams, according to $G_{B} M_{1}$ and $G_{B} M_{2}$, in group $A$ was 8 (8A), in $B$ was 1 (1B), in C it was 4 (4C), and in $D$ the team 6 (6D). Of all, only a team from group B got the highest grade of its group, which means that the balance of Belbin roles has a relationship to their performance. However, this is not the case for the rest of the teams. Indeed, team 8A, which is the most balanced team of all those analyzed, did not get the highest grade in its group. On the other hand, if a balanced team performs well, an unbalanced team would do the opposite. So, the most unbalanced teams, considering the same $G_{B M}$ and $G B M_{2}$, were: $4 A, 3 B$, $5 C$, and $5 D$. Again in group $B$, that premise is met. It is also true for group $C$, but not for groups $A$ and $D$, whose scores are one of the highest. When analyzing the $\mathrm{GBM}_{3}$ and $\mathrm{GBM}_{4}$, the most balanced would be $1 \mathrm{~A}, 2 \mathrm{~B}, 3 \mathrm{D}$, and $7 \mathrm{D}$, and the most unbalanced would be $3 \mathrm{~A}, 6 \mathrm{~A}, 7 \mathrm{~A}, 8 \mathrm{~A}, 5 \mathrm{~B}, 4 \mathrm{C}, 5 \mathrm{C}, 5 \mathrm{D}$. There was a positive relationship with 
performance only in group $B$ since $2 B$ obtained the highest final grade. Likewise, the 7D team got a high score, but not the highest. In group $A$, one of the unbalanced teams scored the highest in the group. Something similar happened in group $D$, where the unbalanced $5 D$ team obtained the second-best grade in its group. Only in group $\mathrm{C}$, one of the unbalanced teams $(5 \mathrm{C})$ got the lowest final grade in its group. As a complement to the previous analysis, a new one was performed including all data to look for trends. For this, a scatterplot was plotted with the final grades data and the GBMs values, as shown in Figure 2.

Figure 2

Scattterplot of Group Balance Metrics (GBMs) and the final grades

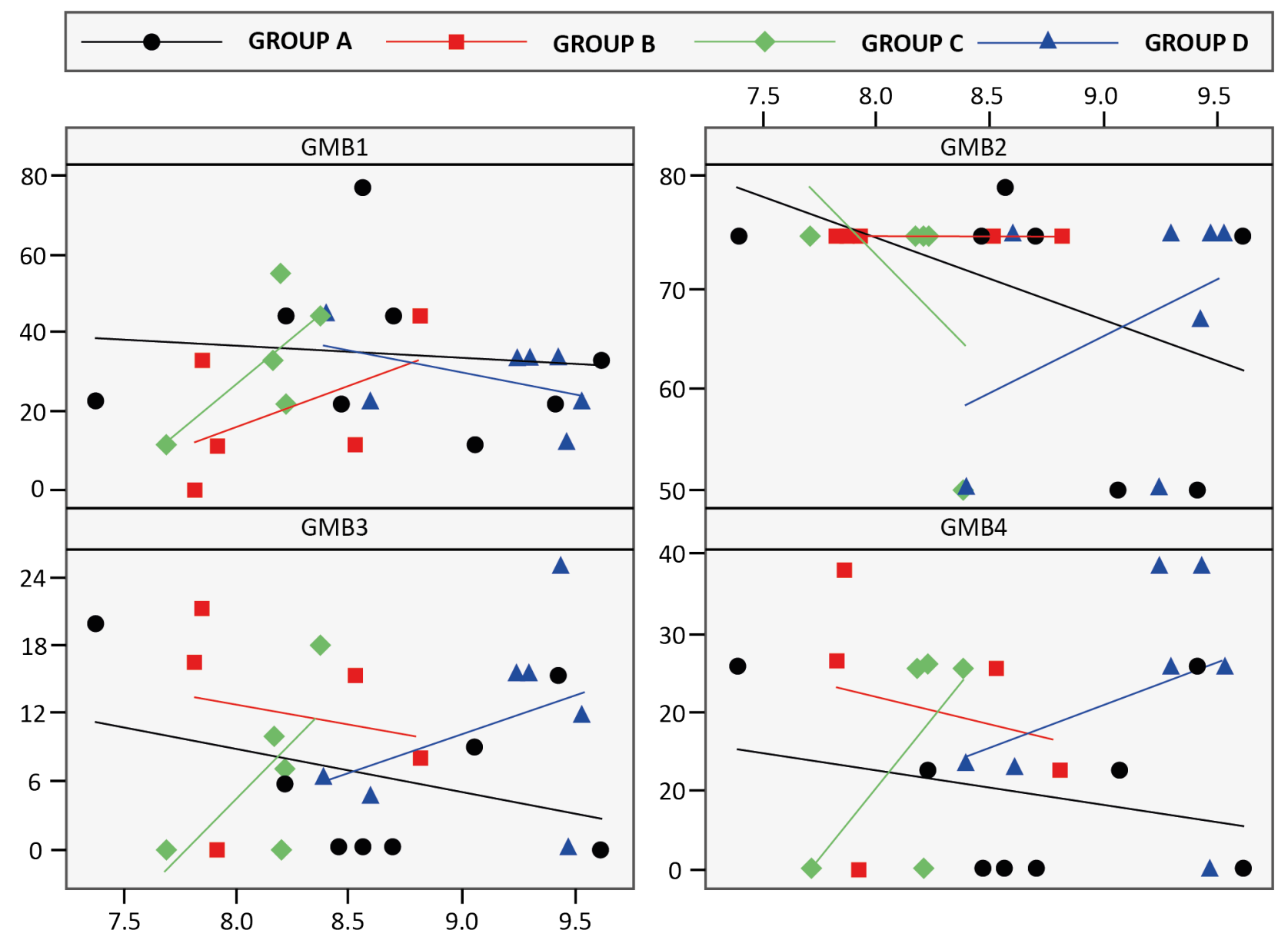

TEAMS' FINAL GRADES

Source: Prepared by the author based on this study results

In the figure 2, linear regression lines were also included. These lines should have a positive slope since in higher GMBs the team would perform better and vice versa. This statement is true for groups $B$ and $D$ in $G_{B} M_{1}, B$, and $D$ in $G_{B M}, C$ and $D$ in $G_{B M}$ and $G_{B M}$. Therefore, the teams of groups $C$ and $D$ are the ones that are more related to the performance. The next group is $B$ with some trend, and the group $A$ without any relationship. Interestingly, this relationship is more noticeable in postgraduate students than undergraduate students. Based on these trends, it intended to calibrate regression equations, using the Stepwise Regression procedure, but no GBM was statistically significant at $95 \%$ reliability to predict the team's final grades. Therefore, it can be said that there is no relationship between the balance of the team and its performance in the four groups analyzed. This result answers the first research question.

Now, it is challenging for a single value, such as the GBMs, to cover everything that involves teamwork. The complexity of the team roles and their relationships does not facilitate quantitative comparison (Smith et al., 
2012). Besides, individuals could adopt several different roles in the team depending on the needs of the team (Sommerville \& Dalziel, 1998), which may affect having a clear response between roles and performance. Therefore, it performed a more detailed analysis using the nine roles in each team and their relationship with the final grades. This analysis helped to answer the second question. First, a scatterplot of the team roles and the final grades were plotted (see figure 3). Regression lines were also placed on that figure to analyze trends. Based on these trends, Table 3 was made.

Figure 3

Scattterplot of nine Belbin roles in the teams and their final grades

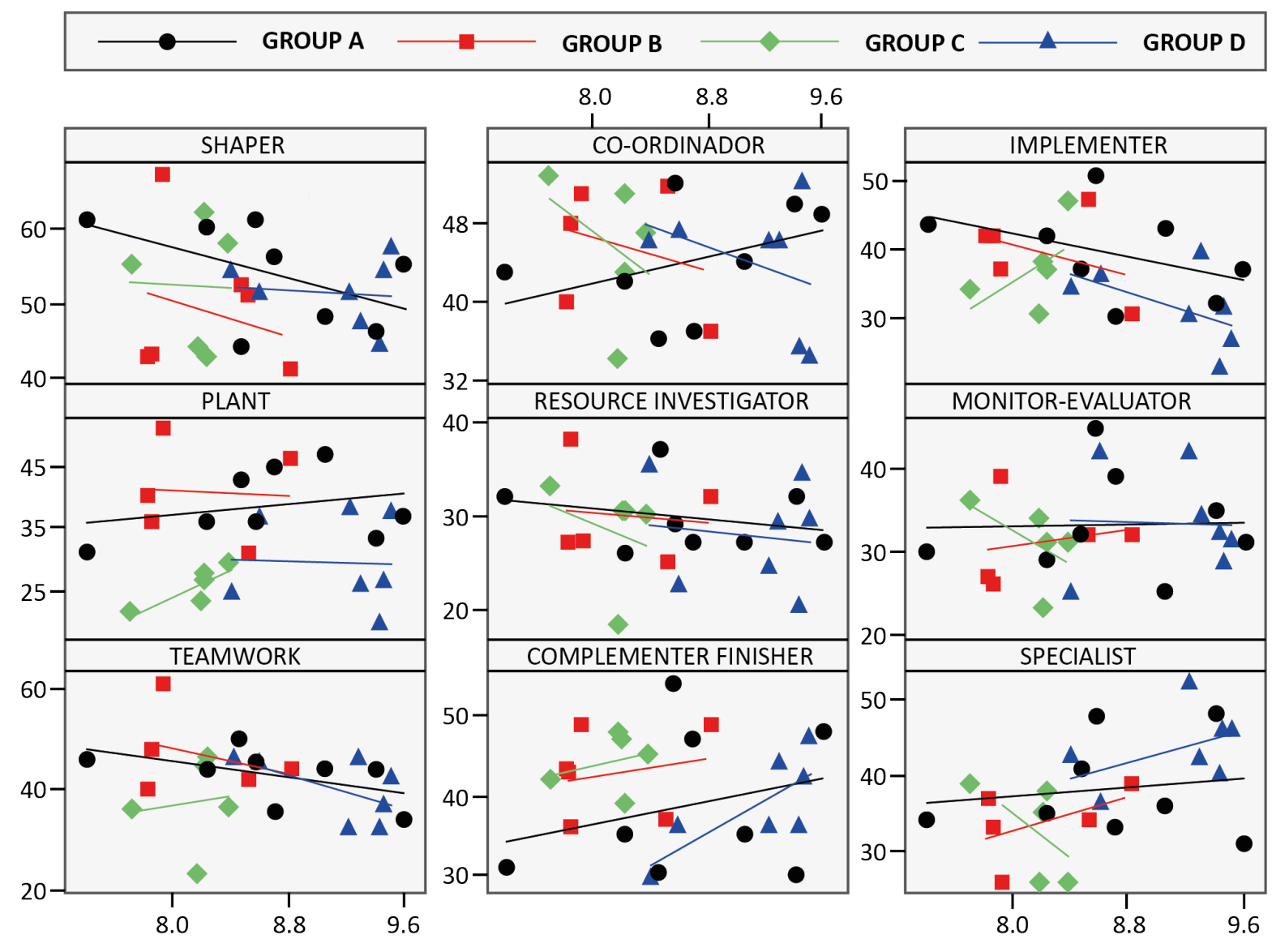

TEAMS' FINAL GRADES

Source: Prepared by the author based on this study results

Table 3

Positive (+) or negative (-) relationship between Belbin's team roles in the teams and final grades

Belbin team roles

\begin{tabular}{|c|c|c|c|c|c|c|c|c|c|}
\hline \multirow{2}{*}{ Group } & \multicolumn{9}{|c|}{ Belbin team roles } \\
\cline { 2 - 10 } & SH & CO & IM & PL & RI & ME & TW & CF & SP \\
\hline A & - & + & - & + & - & + & - & + \\
\hline B & - & - & - & - & - & + & - & + \\
\hline C & - & - & + & - & - & - & + & + \\
\hline D & - & - & - & + & - & - & - & + \\
\hline
\end{tabular}

SH: Shaper, CO: Co-ordinador, IM: implementer, PL: plant, RI: Resource Investigator, ME: monitor-evaluador, TW:

Teamworker, CF: Complementer finisher, SP: Specialist

Source: Prepared by the author based on this study results 
In table 3, roles that have similar trends in all groups are $\mathrm{SH}, \mathrm{RI}$, and $\mathrm{CF}$. This trend means when the accumulating score is high in $\mathrm{SH}$ or $\mathrm{Rl}$, the team will have a high final grade, and the opposite will happen with the accumulated score in CF. Likewise, the roles that have similar trends in almost all the groups (3 out of 4) are CO, IM, TW, and $\mathrm{SP}$, with similar relationships as the previous two roles. These trends are not conclusive since their statistical correspondence must be analyzed. So it performed a Stepwise Regression procedure with the statistical software. In the undergraduate student groups ( $A$ and B) there was no statistical relationship between team roles and final grades, while in the postgraduate groups $(C$ and $D)$ there was. In group $C$, the most influential roles were: $\mathrm{PL}, \mathrm{RI}$, and $\mathrm{SH}$, while in group $\mathrm{D}$ they were $\mathrm{CF}, \mathrm{TW}$, and $\mathrm{PL}$. The common role of these two groups was $\mathrm{PL}$. These roles, despite being influential for the final grades, not all have statistical significance ( $95 \%$ reliability). Table 4 shows the equations calibrated for groups $C$ and $D$, which confirms the relationship between the roles of Belbin teams and their performance. This result answers the second research question. In those equations, PL and CF have a positive influence, while TW has a negative one. The fact that TW is negative contradicts what is mentioned in the Belbin theory (Belbin, 1981); therefore, a possible explanation is that the combination with TW and other roles causes a decrease in the performance of the team. It is notable that in the group $D$ equation, the Plant role was just on the edge of the significance level $(p=0.005)$. Regardless of the calibrated values in these equations since they may deviate in other groups or studies, the main result is that, in fact, the roles (measured by Belbin) have a significant impact on the final grades of postgraduate students. In a previous studies, the Coordinator and Specialist were the most influential roles (García-Ramírez, 2020), Co-ordinator, Plant, Completer finisher, and Teamworker (Prichard \& Stanton, 1999), or Implementer, Shaper and Co-ordinator (Sommerville \& Dalziel, 1998). This means that those found in this research are consistent with previous research.

Table 4

Calibrated equations with the most statistically significant Belbin roles

\begin{tabular}{|c|c|c|c|c|c|c|c|c|}
\hline Group & Predictor & Coef. & SE Coef. & $T$ & $\mathbf{P}$ & $S$ & $\mathbf{R}^{2}$ & $R^{2}$ adj \\
\hline \multirow{2}{*}{ C } & Constant & 6.35 & 0.56 & 11.30 & 0.001 & \multirow{2}{*}{0.14} & \multirow{2}{*}{0.77} & \multirow{2}{*}{0.70} \\
\hline & PL & 0.07 & 0.02 & 3.20 & 0.049 & & & \\
\hline \multirow{3}{*}{ D } & Constant & 8.56 & 0.45 & 18.90 & 0.000 & \multirow{3}{*}{0.13} & \multirow{3}{*}{0.95} & \multirow{3}{*}{0.92} \\
\hline & $\mathrm{CF}$ & 0.06 & 0.01 & 7.05 & 0.002 & & & \\
\hline & TW & -0.04 & 0.01 & -5.23 & 0.006 & & & \\
\hline \multicolumn{9}{|c|}{ PL: Plant, CF: Completer finisher, TW: Teamworker } \\
\hline
\end{tabular}

\subsection{Students coments}

Before analyzing the students' comments, they were asked to rate the overall experience in every course $(1=$ very poor, 10 = excellent). The results were as follows: group A: 6.95 [6.40, 7.50], group B: 7.86 [7.21, 8.51], group C: 8.63 [8.15, 9.11] and group D: 9.06 [8.73, 9.39]. As can be seen, the scores received by undergraduate students are lower than those of postgraduate students, which may have influenced the general perception of teamwork. Groups $C$ and D were also asked if it was useful to know the role of the team members $(1=$ useless, $10=$ very useful), whose results were high and very similar, in group C: $7.75[7.08,8.42]$ and group D: 7.18 [6.29, 8.07].

Regarding teamwork, 27 students in group A commented about teamwork. From these students, 56\% had a positive vision of teamwork (organization of the teams, project development, academic challenge, etc.), and $44 \%$ highlighted the negative things (working with other students with whom were not used to, lack commitment of its members, etc.). In group C, ten students made some comments about the teamwork. Forty percent (4/10) mentioned positive elements about teamwork, while 60\% (6/10) commented negatively about it. The positive or negative comments were very similar to those in group $A$. In group $C$, nine students mentioned something 
regarding teamwork. From this number, 78\% (7/9) highlighted the strengths of the distribution of the teams for the development of the project, while $22 \%$ of the students $(2 / 9)$ mentioned that they did not agree with the teams or that this team distribution made academic activities difficult. In group $D$, five students commented on teamwork, where four students $(80 \%)$ mentioned that the distribution of teams was correct, while one student (20\%) considered that the distribution was not adequate. Interestingly, the two undergraduate groups have very similar results, in which around $50 \%$ disagree with the teams or the teamwork, possibly because they are not used to working under the online sessions, lack of commitment, or they think it will not be useful during their academic training. On the other hand, the postgraduate groups also have similar values to each other. However, there had more positive than negative comments, possibly because teamwork is more common in their jobs than in a university. Besides, they are more exposed to work in teams, due to the age of the participants and jobs. This result is similar to another study where students answered well to the Belbin scheme, they were able to identify links between group work and employability and recognized the usefulness of such team role models (Smith et al., 2012). All these comments and trends are consistent with the previous analysis where there were differences between undergraduate and graduate students.

\section{Conclusions}

The objective of this study was to analyze whether there is a relationship between Belbin's team role results and their performance in road design courses. To achieve it, four groups of students (undergraduate and postgraduate) participated to answer two research questions. From the results study, the main conclusions are presented below.

In the first analysis, no consistent relationship was shown between the team's role balance and its performance across all teams. In some cases that relationship was true and positive; while in others, the opposite happened; that is, an unbalanced team got a high final grade. Therefore, it is understandable that in the previous literature, mixed results have been found using the Belbin tool. These differences may be because the complexity of the team roles is not fully addressed with Group Balance Metrics or it must be completed with other variables of the individual or of the people who have worked with that individual, which was conducted in previous studies; however, it was not used in Civil Engineering. This could be analyzed in future studies.

From the second analysis, it was found that the most influential roles in performance are Plant $(+)$, Complementer finisher (+), and Teamworker (-), but this was only applicable for teams of postgraduate students. The difference between students was not only in this result but also in their perception of teamwork. This outcome suggests that the tool is more applicable to the workplace, which is where it was developed, than to individuals who have not yet had work experience, such as undergraduate students. The difference between undergraduate and postgraduate students should be deepened in later studies.

This study has several limitations. First, it studied 25 teams (approximately five students per team). It is based only on a road engineering subject at one university in Ecuador. However, it is generally one of the subjects in which traditional teaching methods are still used. The development of the courses was carried out online and not face-to-face, where the students' interactions are different. However, this method applies to distance learning where there are interactions with the teacher synchronously. Also, it assumed that the final grades were team performance. However, despite these limitations, the study deepens the relationship between Belbin's roles and team performance in Road and Civil Engineering. It found trends in the nine roles for the four courses, which could be typical of Civil Engineers. It showed differences between undergraduate and postgraduate students. It showed that some roles influence the performance the most. It presented the student distribution methodology based on the cluster analysis of the individual results of the Belbin survey. The study also offers a 
methodological contribution that can be used in future studies. Also, it will help teachers that are interested in developing students teamwork competence.

\section{Bibliographic references}

Aguilar, R., Muñoz, M., Díaz, J., \& Ucán, J. (2020). Exploring the influence of belbin's roles on software requirements specification. RISTI - Revista Ibérica de Sistemas e Tecnologias de Informação, 36(03), 34-49. https://doi.org/10.17013/risti.36.34-49

Belbin. (2019). Northumbria University. https://www.belbin.com/about/higher-education/northumbriauniversity/

Belbin, M. (1981). Management teams, why they succeed or fail. Heinemann.

Belbin, M. (2009). Method, reliability \& validity, statistics and research: A comprehensive review of Belbin team roles. https://www.belbin.com/media/1158/belbin-uk-2014-a-comprehensive-review.pdf

Blenkinsop, N., \& Maddison, A. (2007). Team roles and team performance in defence acquisition. Journal of Management Development, 26(7), 667-682. https://doi.org/10.1108/02621710710761298

Curşeu, P. L., Janssen, S. E. A., \& Raab, J. (2012). Connecting the dots: Social network structure, conflict, and group cognitive complexity. Higher Education, 63(5), 621-629. https://doi.org/10.1007/s10734-011-94627

Curşeu, P. L., \& Pluut, H. (2013). Student groups as learning entities: The effect of group diversity and teamwork quality on groups' cognitive complexity. Studies in Higher Education, 38(1), 87-103. https://doi.org/10.1080/03075079.2011.565122

García-Ramírez, Y. (2020). Roads project: the relationship between team roles and their performance. XV Latin American Conference on Learning Technologies.

Gutiérrez, L., Flores, V., Keith, B., \& Quelopana, A. (2019). Using the Belbin method and models for predicting the academic performance of engineering students. Computer Applications in Engineering Education, 27(2), 500-509. https://doi.org/10.1002/cae.22092

Lupuleac, S., Lupuleac, Z.-L., \& Rusu, C. (2012). Problems of assessing team roles balance-Team. Procedia Economics Ans Finance, 3, 935-940. https://doi.org/10.1016/S2212-5671(12)00253-5

McCune, V., \& Entwistle, N. (2011). Cultivating the disposition to understand in 21st century university education. Learning and Individual Differences, 21(3), 303-310.

https://doi.org/10.1016/j.lindif.2010.11.017

Meslec, N., \& Curşeu, P. L. (2015). Are balanced groups better? Belbin roles in collaborative learning groups. Learning and Individual Differences, 39, 81-88. https://doi.org/10.1016/j.lindif.2015.03.020

Moraes, J. L., \& Loos, M. J. (2017). The importance of balancing personalities for the formation of teams in a food industry. Espacios, 38(61). https://www.revistaespacios.com/a17v38n61/a17v38n61p27.pdf

Partington, D., \& Harris, H. (1999). Team role balance and team performance: An empirical study. Journal of Management Development, 18(8), 694-705. https://doi.org/10.1108/02621719910293783

Prichard, J. S., \& Stanton, N. A. (1999). Testing Belbin's team role theory of effective groups. Journal of Management Development, 18(8), 652-665. https://doi.org/10.1108/02621719910371164 
Smith, M., Polglase, G., \& Parry, C. (2012). Construction of Student Groups Using Belbin: Supporting Group Work in Environmental Management. Journal of Geography in Higher Education, 36(4), 585-601. https://doi.org/10.1080/03098265.2012.692156

Sommerville, J., \& Dalziel, S. (1998). Project teambuilding - the applicability of Belbin's team-role selfperception inventory. International Journal of Project Management, 16(3), 165-171. https://doi.org/10.1016/S0263-7863(97)00054-9

State College. (2005). Minitab 14.2 Statistical Software [Computer program] (14.2). PA: Minitab, Inc. www.minitab.com

Stevens, M. J., \& Campion, M. A. (1999). Staffing work teams: Development and validation of a selection test for teamwork settings. Journal of Management, 25(2), 207-228. https://doi.org/10.1177/014920639902500205

van de Water, H., Ahaus, K., \& Rozier, R. (2008). Team roles, team balance and performance. Journal of Management Development, 27(5), 499-512. https://doi.org/10.1108/02621710810871817

Zoom Video Comunications Inc. (2020). Zoom Video Comunications. https://support.zoom.us/hc/es

Esta obra está bajo una Licencia Creative Commons Attribución-NoCommercial 4.0 International

(cc) EY-NC 